PI.S() IPNC (W.?

\title{
Genotypic diversity in pearl millet (Pennisetum glaucum) for nitrogen, phosphorus and potassium use efficiencies*
}

\author{
S.P. WANI, M.A. ZAMBRE and K.K. LEE \\ Internutional Crops Reseurch Instimue for the Se'mi-Arid Tropics (IC RISAT). Putuncheru P.(). S(I) .324. \\ A.P.. India
}

Key words: genetic diversity, grain yield, harsest index, nutrient uptake, pearl millet, Pe'nnise'tum glaucum (L..) R.Br., translocation index

\begin{abstract}
Twelve genotypes of pearl millet (Penmisetum glancum (L.) R.Br. comprising of hybrids, composites, varieties, and landraces were 'evaluated for N. P. and K uptake, efficiency of grain production per unit of $N, P$, and $K$ absorbed and their efficiency of transfer from vegetative parts to the grain. The genotypes were grown on Alfisols in two fields at the ICRISAT (entre with two $\mathrm{N}$ and $\mathrm{P}$ levels in a rainy scason (20 kg N $+9 \mathrm{~kg} P$ ha ${ }^{\prime}$ and $80 \mathrm{~kg} \mathrm{~N}+18 \mathrm{~kg} P$ ha ' ').

Genotypes varied significantly for total dry matter. grain yield. and for uptake. use efficiency and translocation indices of N, P. and K. Genotype $\times$ fertility interactions were not observed for all parameters studied, exeept for grain yield, indicating that genotypes could be evaluated for N. P. and K use efficiency and translocation indices at different soil fertility levels. Hybrid MBH 110 showed the highest use efficiency for $N, P$, and $K$ with a maximum harvest index, and it was followed by two other hybrids amongst the genotypes tested. Genotypes (composites, and a landrace) which showed lower use efficiency and translocation indices for N, P, and $K$ also had lower grain yields than the hybrids tested. Positive relationships were found between harvest index and phosphorus use efficiency, and $N$, and $P$ translocation indices. Thus, a future challenge lies in selecting lines with high N, P. and K use efficiency and translocation indices.
\end{abstract}

\section{Introduction}

Pearl millet is an important rainfed cereal crop grown on marginal soils in the semi-arid tropics. Most of it is grown with little or without fertilizer applied. Nitrogen is usually the nutrient limiting crop production and its poor recovery by crops, when applied as fertilizer, is of worldwide concern. With steadily increasing prices of fertilizers, it becomes important to produce maximum pearl millet grain yields per unit of fertilizer applied. In recent years, crop improvement research specifically directed towards increasing

\footnotetext{
- Submitted as CP \# 522 by the International Crops Research Institute for the Semi-Arid Tropics (ICRISAT).
}

the efficiency of mincral nutrition of plants has received increased attention (Devine. 1982; Gabelman and Loughman, 1987; Sarić and Loughman, 1983). The differential response of pearl millet genotypes to applied N (ICRISAT, 1988; Kanwar et al., 1973; Murty, 1967) suggests that differences in nutrient uptake and translocation to the grains exist in pearl millet genotypes. Nutritional differences in genotypes have rarely been related to final economic yicld. Increased and efficient production of pearl millet may be charcterised as functions of increased uptake and accumulation of nutrients by the plant, increased production of dry matter per unit of nutrient assimilated, and increased translocation of nutrients from vegetative parts to the grain. 
Genotypes differences with respect to $\mathrm{N}, \mathrm{P}, \mathrm{K}$ and other nutrients for the abovementioned traits have been reported in sorghum (Seetharama et al., 1987). This paper deals with differences among a set of 12 pearl millet genotypes grown at two levels of applied $\mathrm{N}$ and $\mathrm{P}$ fertility. The genotypes were compared for the extent of variation in the abovementioned traits and for the relationships between grain yield and some of these traits.

\section{Materials and methods}

\section{Experimental details}

Twelve pearl millet genotypes selected for this study consisted of three hybrids (BJ I(14, MBH 110, and ICMH 451) released for commercial cultivation in India, five composites (MC-C8, D2 C6, ERC-Co, EC-C6 and IVC-C7) made at ICRISAT, one composite (RCB 2) released for cultivation in Rajasthan. India, a synthetic (Gam 73) from Senegal, and Local landraces from India (Rajasthan Locals $I$ and 2). The experiment was conducted in two ficlds (locations) (Table 1) during the rainy season on Alfisols at ICRISAT Center, Patancheru, India $\left(17^{\circ} 36^{\prime} \mathrm{N}\right.$, $78^{\circ} I 6^{\prime} \mathrm{E}, 54.5 \mathrm{~m}$ altitude).

Both experiments were conducted in a splitplot design with two $\mathrm{N}$ fertility levels as main plots and pearl millet genotypes as sub-plots.

Table 1. Details of Altisols at ICRISAT Center, 1987 rainy season. and of ficld experiments

\begin{tabular}{|c|c|c|}
\hline Properties & Location I & Location II \\
\hline Soil pH & $6.60)$ & $7 .(x)$ \\
\hline EC (M mhos cm ') & 0.14 & 0.24 \\
\hline $\begin{array}{l}\text { Organic carbon } \\
\left(\mathrm{g} \mathrm{kg}^{\prime}\right)\end{array}$ & 3.40 & 3.311 \\
\hline $\begin{array}{l}\text { Available P } \\
\text { (mg kg ') }\end{array}$ & 14.7 & 14.3 \\
\hline $\begin{array}{l}\mathrm{NO}_{3}-\mathrm{N}+\mathrm{NH}_{4} \cdot \mathrm{N} \\
\left(\mathrm{mg} \mathrm{kg}{ }^{\prime}\right)\end{array}$ & 19 & 20.0 \\
\hline $\begin{array}{l}\text { Total N } \\
\qquad\left(\mathrm{mg} \mathrm{kg}^{-1}\right)\end{array}$ & 410 & 410 \\
\hline Gross plot area $\left(\mathrm{m}^{2}\right)$ & 40.5 & 24 \\
\hline Harvest area $\left(\mathrm{m}^{2}\right)$ & 36 & 13.5 \\
\hline Date of sowing & 17 June 87 & 16 June 87 \\
\hline Date of irrigation & - & $\begin{array}{l}22 \text { July and } \\
4 \text { August } 87\end{array}$ \\
\hline
\end{tabular}

Each treatment was replicated four times. For the $20 \mathrm{~kg} \mathrm{~N}$ ha ' treatment $20 \mathrm{~kg} \mathrm{~N}$ ha ${ }^{-1}$ as urea and $9 \mathrm{~kg} \mathrm{Pha}{ }^{-1}$ as single super-phosphate were applied as basal dressings. For the $80 \mathrm{~kg} \mathrm{~N}$ ha ${ }^{\prime}$ treatment a basal dose of $40 \mathrm{~kg} \mathrm{Nha}^{\prime}$ and $18 \mathrm{~kg} P$ ha ' was applied. The remaining $N$ was applied. The remaining $N$ was applied as urea after thinning (20 DAS). The crop was machine sown on ridges spaced $0.75 \mathrm{~m}$ apart. and plantto-plant spacing of $0.1 \mathrm{~m}$ was maintained by thinning the plants 12 DAS. Weeding and interrow cultivations were carried out as and when required.

At harvest, the above-ground plant parts were harvested. The panicles were separated and threshed. Fresh stover yield was recorded and 1()-kg subsamples of stover were collected and chopped. The subsampled stover biomass and the grains were dried at $71^{\circ} \mathrm{C}$ for $72 \mathrm{~h}$ and their dry mass recorded. $\mathrm{N}$ and $\mathrm{P}$ in ground grains and in stover were determined with the use of a Technicon Autoanalyser, and $\mathrm{K}$ was determined using atomic absorption spectrophotometry (Jackson, 1973).

\section{Characterstics used to compare genotypes}

The traits used to characterise the genotypes were i) total dry matter production (grain plus stover), ii) harvest index /HI: (grain mass/total dry matter mass $\times(1(0)$ ). iii) $\mathrm{N}, \mathrm{P}$ and $\mathrm{K}$ contents of grain and stover (dry mass multiplied by concentrations in the respective parts), iv) total $N, P$, and $K$ in plants (contents in grains + contents in stover), v) N, P, and K use efficiency (NUE, PUE and KUE: grain mass produced per unit of N, $P$, and $K$ in total dry matter), vi) N, $P$, and $\mathrm{K}$ translocation indices (NTI, PTI and $\mathrm{KTl}$ : $N, P$, and $K$ contents in grains divided by $N, P$, and $\mathrm{K}$ contents in total dry matter $\times 10())$.

\section{Results}

Grain and total dry matter yield, and total $N, P$, and $K$ uptake

Mean grain and total dry matter yields of pearl millet across the genotypes and locations increased significantly to $3.10 \mathrm{tha}^{-1}$ and $7.90 \mathrm{tha}^{-1}$ 
(a)

(a)
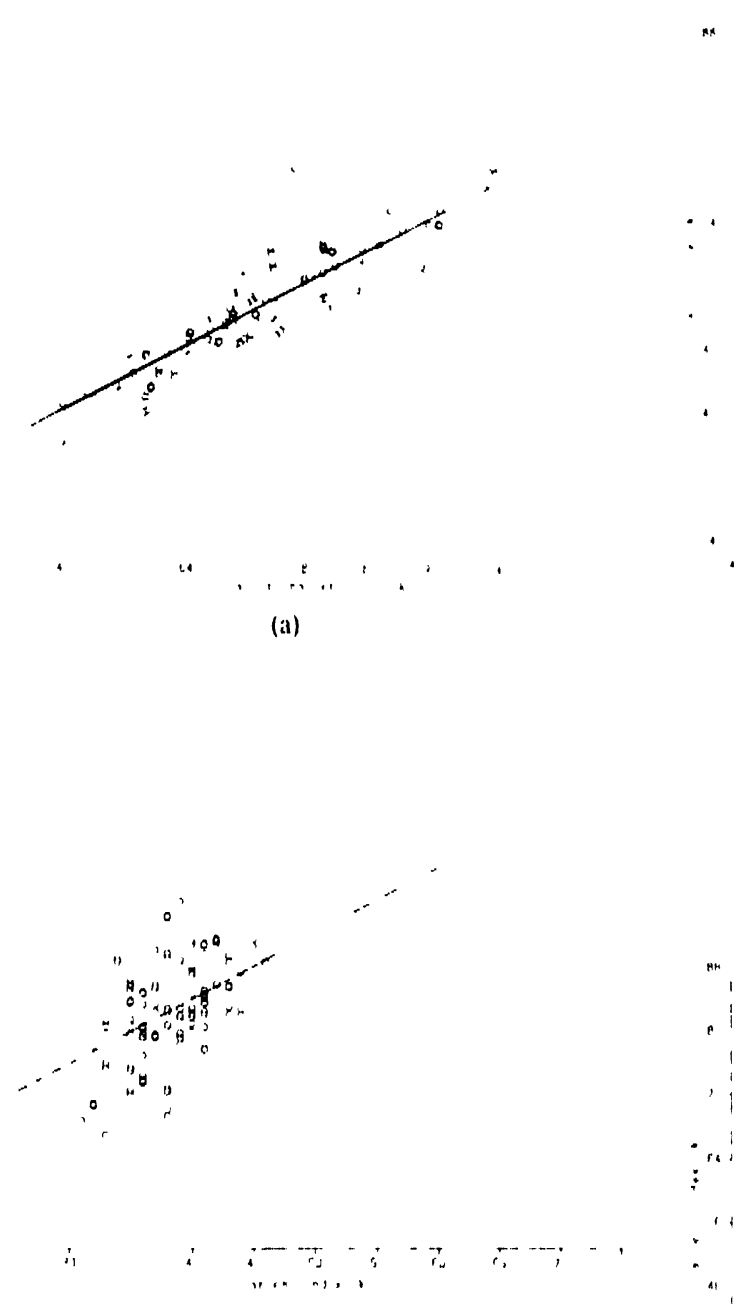

(b)

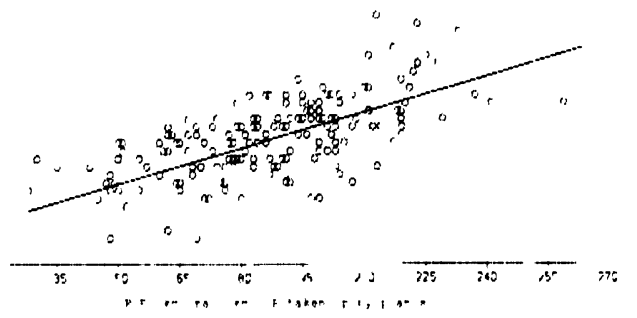

(c) (d)

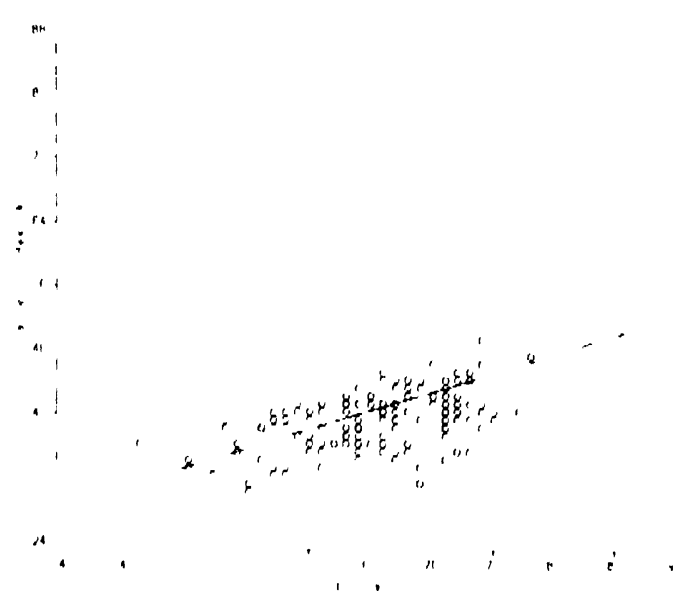

(c)

Fig I a Relationship between total dry matter yicld ( $\mathrm{kg}$ ha ') and grain yield ( $\mathrm{kg}$ ha ') of pearl millet genotypes. $y=84+0.380 \times\left(R^{2}=\left(167^{*}\right.\right.$ ". $d f=19(0)$ b Relationship between grain yield (kgha ') and harvest index (HI \%) of pearl millet genotypes $y=472+(x) 10 \times\left(R^{\prime}=\left(0.28^{* *}\right.\right.$, $\mathrm{df}=$ 19(1)) c Relationship between phosphorus use efficiency (PUE) and harvest index (HI) of pearl milet genotypes. $y=864+0162 \times\left(R^{2}=\left(148^{* *}, d f=191\right)\right)$. d. Relatıonship between harvest index $(\mathrm{HI})$ and nitrogen translocation index (NTI) of pearl millet genotypes. $y=1.41+0.589 \times\left(R^{2}=\right.$ () $44^{*}, \mathrm{df}=19(1)$ e Relationship between harvest index (HI) and phosphorus translocation index (PTI) of pearl millet genotypes $y=7.86+\left(0.478 \times\left(R^{2}=0.38 * *, d f=19()\right)\right.$. 
598 Wani ct al.

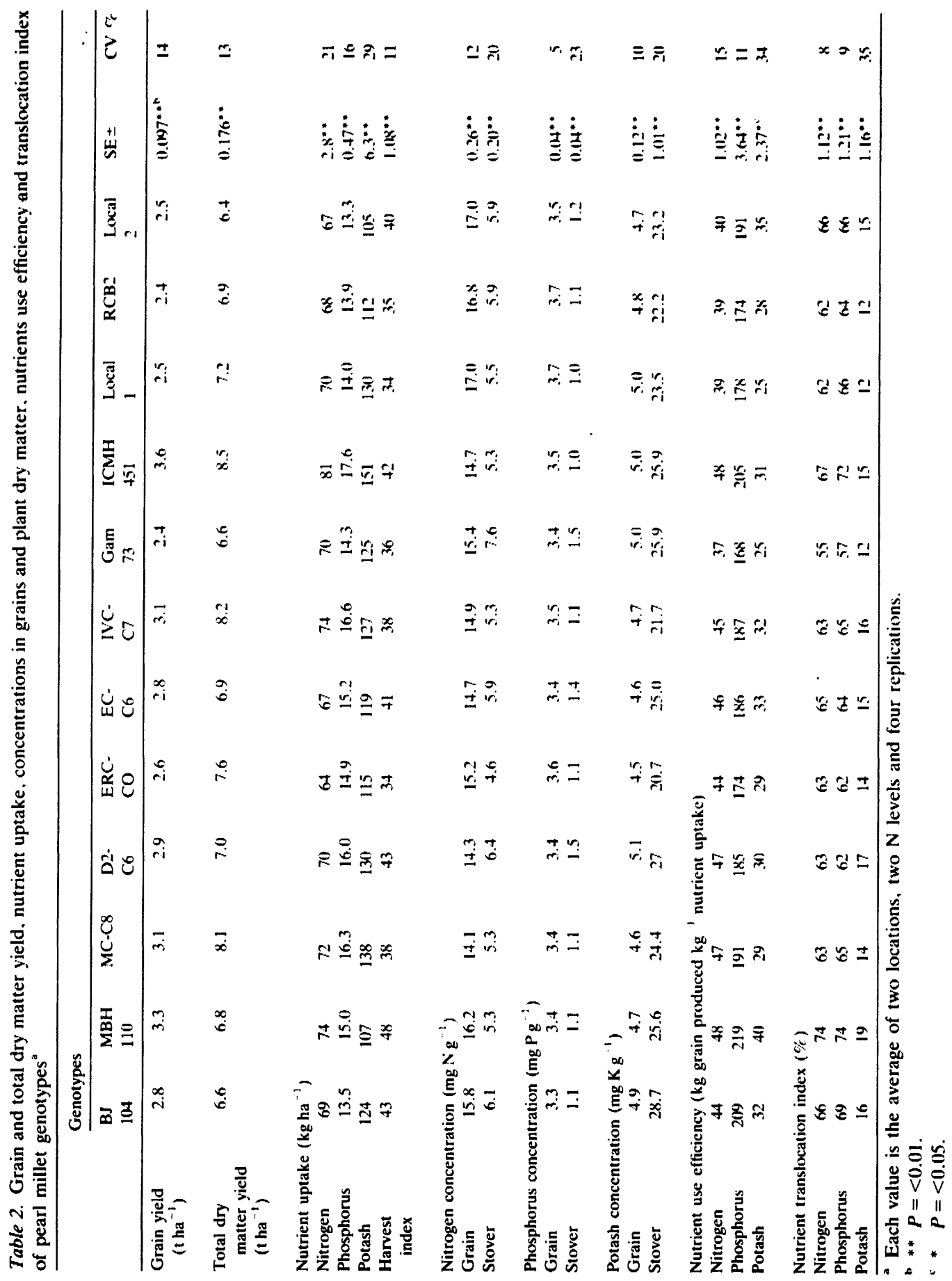


respectively, with $80 \mathrm{~kg} \mathrm{Nha}^{-1}$ applied as compared to 2.55 t ha ' and 6.50 t ha 1 respectively. with $20 \mathrm{~kg} \mathrm{~N} \mathrm{a}^{-1}$ applied. In all genotypes. except D2C6' and IVC-C7. application of $80 \mathrm{~kg} \mathrm{~N} \mathrm{ha}^{\prime}$ increased the grain yiclds signiticantly over those obtained with $20 \mathrm{~kg} \mathrm{~N}$ ha 1 treatment. However, for total dry matter, the genotype $x$ fertility level interactions were not significant. Even though grain and dry matter yields varied between locations, there were no genotype $\times$ location interaction effects for these parameters. Mean grain and total dry matter yiclds of pearl milet genotypes across the fertility levels and locations varied significantly. The landraces from India (Rajasthan Locals 1 and 2) produced dry matter yields similar to those of improved varictics and hybrids (Table 2). A maximum mean grain yicld of $3.6 \mathrm{tha}{ }^{\prime}$ was observed for hybrid ICMH 451. followed by another hybrid $\mathrm{MBH} 110$. Total N, P. and $\mathrm{K}$ uptake varied significantly (Table 2). However, total N, P, and K uptake hy landraces and some of the improved genotypes were similar. There was a positive relationship $(\mathrm{df}=190)$ between grain mass and total dry matter $\left(\mathrm{R}^{2}=0.67^{* *}\right.$. Fig. la), grain mass and $H I\left(R^{2}=0.28^{* *}\right.$, Fig. lb), grain mass and total $N\left(R^{2}=-0.53^{* *}\right), P$ $\left(R^{2}=0.71^{* *}\right)$ and $K\left(R^{2}=0.31^{* *}\right)$, uptake respectivcly.

\section{Harvest index and nutrient translocation indices}

Application of $80 \mathrm{~kg} \mathrm{~N}{ }^{\prime}{ }^{1}$ or field location (or fertility treatment) had no effects on $\mathrm{HI}$ of pearl millet genotypes. The HI varied significantly amongst genotypes. The improved hybrids and the composites, except ERC-Co (an ergot-resistant composite), had higher $\mathrm{HI}$ than the local landraces (Table 2). Harvest index was positively correlated with PUE $\left(R^{2}=0.48^{* *}\right.$, df $=190$, Fig. 1c).

NTI of pearl millet genotypes did not change with $80 \mathrm{~kg} \mathrm{Nha}^{-1}$ applied in comparison with $20 \mathrm{~kg} \mathrm{Nha}^{-1}$. However, NTI varied significantly among locations, but without genotype $x$ location interactions. Mean PTI of pearl millet across the locations increased significantly to $68.2 \%$ when $\mathrm{N}$ was increased from 20 to $80 \mathrm{~kg} \mathrm{ha}^{-1}$, whereas in that situation mean KTI decreased from $16.5 \%$ to $13 \%$. Nutrient translo- cation indices varied significantly amongst genotypes. In general, the genotypes with higher HI showed higher mutrients translocition indices (Table 2). Higher proportions $(>0() \%)$ of plant $\mathrm{N}$ and $\mathrm{P}$ were translocated to the grains, whereas $<80$ \%' of total plant $\mathrm{K}$ rentained in the stover. More variability for NTI and PTI than for KTI was observed (Table 2). There was a positive relationship $(\mathrm{df}=19(1)$ hetween $\mathrm{HI}$ and NTI $\left(R^{2}=0.44^{* *}\right.$. Fig. Id) and also with P'Tl $\left(R^{2}=\right.$ ().38**, Fig. 1c).

\section{Nutriemt $(N, P, K)$ concentrutions in grain and stover}

Mean $\mathrm{N}$ concentrations in grain and stover across the genotypes and locations increased significantly from 14 to 17 and from 5.1 io $6.4 \mathrm{mgg}$, respectivcly, with $8\left(0 \mathrm{~kg} \mathrm{~N}\right.$ hal ${ }^{1}$ instead of $20 \mathrm{~kg} \mathrm{~N}$ hal applied. Phosphorus concentration in grains was not changed, whereas $P$ concentration declined significantly from $1.3 \mathrm{mgg}$ 'to $1.177 \mathrm{mgg}{ }^{\prime}$ dry matter when $\mathrm{N}$ application was increased from 20 to $80 \mathrm{~kg}$ ha ! Potassium concentration in grains decreased from 4.93 to $4.66 \mathrm{mgg}$ ' when $\mathrm{N}$ applied was increased from 20 to $8(0 \mathrm{~kg}$ ha ', whereas $\mathrm{K}$ concentration in stover was not changed. Locations also had a significant effect on nutrient concentrations in grains and stover.

Mean N, $P$, and $K$ concentrations in grain and stover varied significantly with genotypes. The landraces had higher concentrations in the grains than the improved genotypes. However, N, P, and $\mathrm{K}$ concentrations in stover of local landraces were similar to those in stover of improved genotypes, except for BJ $1(14$ and D2C6 (Table 2). There was no genotype $\times$ fertility interaction for $\mathbf{N}$ concentration in grain and stover, but a significant interaction was observed between genotypes and fertility levels for $P$ and $K$ concentrations in grains and stover. In a few genotypes $P$ and $K$ concentrations in grain and stover increased when $\mathrm{N}$ applied was increased from 20 to $80 \mathrm{~kg} \mathrm{ha}^{-1}$, whereas in others it decreased. Grain $\mathrm{N}$ concentration was positively correlated $(\mathrm{df}=$ 190) with a total $N$ uptake $\left(R^{2}=0.71^{* *}\right)$, and also with total $K$ uptake $\left(R^{2}=0.50^{* *}\right)$ while it was negatively correlated with NUE $\left(R^{2}=\right.$ $\left.0.83^{* *}\right)$, and $\operatorname{KUE}\left(\mathrm{R}^{2}=0.34^{* *}\right)$. 


\section{Nutrient use efficiencies}

Mean NUE of pearl millet genotypes decreased significantly from 48 to $39 \mathrm{~kg}$ grain kg ${ }^{-1}$ plant $\mathrm{N}$ uptake when $\mathrm{N}$ applied was increased from 20 to $8(1) \mathrm{kg}$ ha !. Phosphorus and potassium use efficiencies were not affected by increase in $\mathrm{N}$ applied. Nutrient (N, P, and $K$ ) use efficiencies varied significantly among genotypes and locations, but there were no genotype $\times$ location interactions for N, P, and $K$ use efficiencies. Improved genotypes, e.g. ICMH 451, MBH 110, BJ 1(14, IVC-C7, and MC-C8 with higher grain yields and $\mathrm{HI}$ showed higher $\mathrm{N}, \mathrm{P}$, and $\mathrm{K}$ use efficiencies than the Local landraces. There was no interaction between genotypes and fertility levels for $N, P$, and $K$ use efficiencies.

\section{Discussion}

The pearl millet genotypes tested represented a broad genetic background. They varied significantly in grain and total dry matter yields, and in nutrient use efficiencies and translocation indices. Most of the improved genotypes (hybrids ICMH 45I, MBH 11(), and BJ 104 and composites $\mathrm{MC}$ C8, D2C6, EC-C6, and IVC-C7) showed higher grain yield than the Local landraces (Rajasthan Locals 1 and 2), composites (ERC-Co, RCB 2) and the synthetic variety Gam 73. Differential responses of pearl millet genotypes to $\mathrm{N}$, in terms of grain yicld, were been observed carlier (Kanwar et al., 1973; Murty, 1967). Total plant nutrient uptake (N, P, and K) of local landraces was similar to that of some of the improved genotypes. A large diversity amongst pearl millet genotypes for $\mathrm{N}, \mathrm{P}$, and $K$ use efficiency and $N, P$, and $K$ translocation indices suggest that it is possible to identify pearl millet liacs with high nutrient use efficiencies and high nutrient translocation indices. The improved genotypes with increased grain yields have shown higher NUE, PUE, KUE, NTI, and PTI (Table 2) than the landraces. However, improvements in some of these traits have come inadvertently along with selections made for improving the $\mathrm{HI}$. This is supported by the strong positive relationships between $\mathrm{HI}$ and PUE, NTI, PTI, N, and P (Figs. 1c, d and e). How- ever, no such selection has taken place for $\mathrm{N}$ and $\mathrm{K}$ use efficiencies even though wide diversity for these traits was known to exist. It means that a future challenge exists to incorporate high $\mathrm{N}$ and $\mathrm{K}$ use efficiencies in improved genotypes along with improved dry matter production, $\mathrm{HI}$ and $\mathrm{N}$, $P$, and $K$ translocation indices. Further, there are no genotype $\times$ fertility interactions indicating that genotyes can be evaluated under diversc fertility conditions. However, for improving $\mathrm{N}$ and $K$ use efficiencies, specific selections need to be made different from those for improving PUE or $N$ and $P$ translocation indices. With such directed efforts it should be possible to improve pearl millet grain yields. These results suggest that it is essential to breed genotypes with increased dry matter production, improved nutrient use efficiencies and nutrient translocation indices. A positive relationship between grain yield and total dry matter production and grain yield and $\mathrm{HI}$ suggests that for further improvement of grain yield of pearl millet, it is essential to improve $\mathrm{HI}$ and total dry matter production. Similarly, Phul et al. (1974) observed that in a set of 50 pearl millet genotypes grain yicld was positively correlated with tiller numbers, $\mathrm{HI}$ and flag leaf area. In the past, improved grain yiclds of pearl millet genotypes were obtained mainly through improved $\mathrm{HI}$ rather than improved total dry matter production and total plant nutrient uptake. The recently improved genotypes, like ICMH 451, IVC-C7, and MC.-C8 produced higher grain yiclds than the local landraces. Some of the improved genotypes have normal HI, and the increased grain yields in thesc genotypes came through increased total dry matter production. This suggests a potential for improving total dry matter production as well as $\mathrm{HI}$, which would also improve grain production. Wide diversity exists amongst genotypes for $N, P$, and $K$ concentrations in grain and stover. The local landraces showed higher $\mathrm{N}$ concentrations in grains than the $\mathrm{N}$ concentrations in high-yielding improved genotypes, which was due to a dilution effect in the grain of improved genotypes. Where pcarl millet is grown as fodder or in cases where straw is incorporated into the soil, the priorities will be entirely different. As PUE, NTI and PTI are positively correlated with $\mathrm{HI}$, which in turn determines grain yield, for selection of parents 
and for testing genotypes with possibly improved other traits. it is important to monitor them for nutrient use efficiency and translocation indices to ensure that such traits are not lost in exchange for others.

These studies were conducted in two locations which were only $5 \mathrm{~km}$ apart. Further studies need to be conducted to confirm that no genotype $\times$ location interactions exist for the abovementioned traits.

\section{Acknowledgement}

Wc acknowledge Dr K L Sahrawat's help in chemical analysis of the samples.

\section{References}

Devine T E 1982 Genctic fitting of crops to problem soils. In Breeding Plants for L.ess Favorable Environments. Eds. M
B Christiansen and C F l.ewis. pp 14,3-173. John Wiley and Sons. New York.

Gabelman W H and Loughman B C (lids.) 1487 cienetic Aspects of Plant Mineral Nutrition. Marrinus Nijhoff/Dr. W. Junk Puhlishers, Dordrecht. The Netherlands. $624 \mathrm{p}$. ICRISAT 1489 Annual Repurt 1987. pr 44-\%o Pattancheru. A.P. 5(12 324. India.

Jackson M I. 1473 Ssil Chemical Analysis. Prentici-Hall of India Pvt. L.ti.. New Delhi. $448 \mathrm{p}$.

Kanwar J S. Das M N, Sardanis M (i and Bapalt S R 1973 Are fertilizer applications of jowar. Maiza and bajra coonomical"? Fert. New's I8. 14- 28.

Murty B K 1967 Rosponsc of hylorids of Sorghtum (jowar) and Pe'nnise'tum syphoides (hajra) to nitrogenl. J. Ponstgrad. Sch. IARI 5, 144-157.

Phul P S. (iupta S K and (iill K S 1974 Association analysis of some morphological and physiological traits in pearl millet. Indian J. (icenst. Plant Brecd. 34, 346-3.352.

Saric M R and l.oughman B (' (Fids.) 198.3 (ienctic Aspects of Plant Nutrition. Martinus Nijhoff/Dr. W. Junk Pub. lishers. Dordrecht, The Netherlands. $445 \mathrm{p}$.

Scetharama N. ('lark R 13 and Marranville J W 1987 Surghum genotype differences in uptiake and use efficiency of mineral elements. In (ienetic Aspects of Plant Mincral Nutrition. Eds. W H Gahclman and B (' I,oughman. pp 4,37.443. Martinus Nijhoff/l)r. W. Junk Publishers, Dordrecht. The Netherlands. 